\title{
The Role of Motivation and Creativity in Sustaining Volunteerism of Citizenship for Positive Youth Development after the Great East Japan Earthquake
}

\author{
Mayumi Oie ${ }^{1}$ \\ ${ }^{1}$ Division of Global Social Sciences, Tokyo Woman's Christian University, Tokyo, Japan \\ Correspondence: Mayumi Oie, Professor, Tokyo Woman's Christian University, Zempukuji 2-6-1, Suginami-ku, \\ Tokyo 167-8585, Japan. E-mail: oie@lab.twcu.ac.jp
}

Received: August 24, 2017

Accepted: September 5, $2017 \quad$ Online Published: November 7, 2017

doi: $10.5539 /$ hes.v7n4p61

URL: http://doi.org/10.5539/hes.v7n4p61

\begin{abstract}
This paper examined how the interdisciplinary field of volunteer motivation and creativity research helps improve our understanding of social issues. This research focused on the victims of the Great East Japan Earthquake, which occurred on March 11, 2011, and discussed how volunteer motivations support volunteer activities, positive youth development and citizenship from the perspective of sociocultural and self-determination theories Next, volunteerism based on prosocial behaviors was explored, such as improvement of victims' lives after the disaster. Despite the positive effect of volunteer activities on lifespan youth development, volunteer assistance within the stricken area has gradually declined during the past year compared to the period immediately after the disaster, when there were a substantial number of volunteers. To sustain volunteer motivation for longer periods, interdisciplinary studies within the areas of psychology and leisure are necessary. This research outlined three important interdisciplinary concepts, which are necessary to recover from the disaster: identity formation, collaborative creativity, and community citizenship. Volunteering as extracurricular activities for undergraduate and prospective teachers can strengthen their own and students' rich and deep life course in future.
\end{abstract}

Keywords: volunteer motivation, creativity, sociocultural study, self-determination theory, citizenship, positive youth development

\section{Introduction}

This paper examined how the interdisciplinary field of volunteer motivation and creativity helps improve our understanding of social issues. In this paper the victims of the Great East Japan Earthquake, which occurred on March 11, 2011 were focused on and discussed how volunteer motivations support volunteer activities from the perspective of sociocultural and self-determination theory. Such motivational perspectives are important in addressing potential solutions toward the goal of social recovery. While this paper focuses on earthquake-related issues, the lessons learnt from the Great East Japan earthquake are generally applicable to the field of creativity and motivation studies. Indeed, the Great East Japan Earthquake has created a controversy regarding critical issues in the post-earthquake Japanese society, such as global sharing of the disaster experience, education for disaster prevention, and mental healthcare for the disaster victims. Collaborative, interdisciplinary research projects dealing with volunteerism and citizenship are currently being developed in Japan. Consequently, Japan's recovery process from the earthquake will provide new opportunities and approaches for creativity and volunteer motivation research.

Interdisciplinary research provides opportunities to discuss the issue of volunteerism among many academic fields through the development of integrative, contextual, and theoretically driven critical analyses. First, volunteerism after the Great East Japan Earthquake will be discussed from an interdisciplinary cultural perspective, which links motivation research and creativity. Motivation and creativity are both interdisciplinary domains of psychology to each other. For a person to survive and recover, creativity, which has been found to be associated with intrinsic motivation (Amabile, Goldfarb, \& Brackfield, 1990), is an indispensable ability. Motivation and creativity can provide the basis for volunteerism, which is an intrinsically motivated act and is connected to autonomous behavior. 
Next, volunteerism based on prosocial behaviors, such as improvement of victims' lives after the disaster will be explored. Despite the positive effect of volunteer activities on lifespan youth development, volunteer assistance within the stricken area has gradually declined during the past year compared to the period immediately after the disaster, where there were a substantial number of volunteers. To sustain volunteer motivation for long periods, interdisciplinary studies within the areas of psychology and leisure are necessary. This research outlines three important interdisciplinary concepts, which are necessary to recover from the disaster: identity formation, collaborative creativity, and community citizenship.

\subsection{Views from Cultural Perspectives: Helping Earthquake Victims}

When disaster strikes, what can we do? The comparative method of sociocultural psychology reveals that although feeling, thinking, and acting can take culture-specific forms, the capacity to continually shape and be shaped by the context is universal (Markus \& Kitayama, 2010). In many situations schema is logically based cultural structures, but helping behaviors are common and universal across various global disasters (e.g., earthquake in Haiti, wildfires in Southern California, rioting in Kenya) including the Great East Japan earthquake. Then it should be more strongly emphasized that there are implicitly cultural, domain-specific, and universal schemata among helping behaviors. In the next section, a psychological self-schema model to explain the mechanism of voluntarism as prosocial behavior to encourage earthquake victims universally across cultures and countries.

\section{2 "Kizuna" and the Self-Schema Model}

Self-determination theorists have identified three empirically supported human needs that contribute to motivation: connection to other people, competence, and autonomy (Ryan \& Deci, 2000). The first two needs are not very controversial. Recently, it has been increasingly recognized that connections to other people are fundamental to the social nature of the human species. Self-determination theory provides a method for understanding why youth initially become involved in altruistic behavior such as volunteering.

According to self-determination theory (Ryan \& Deci, 2000), individuals should be motivated to become involved in three contexts: relatedness, autonomy, and competence. Individuals want to be connected to or relate to others. These connections or relations define "relatedness". In addition, individuals are motivated to act based on self-determined reasons rather than external incentives. These self-determined behaviors are referred to as "autonomy". Finally, individuals have a need to demonstrate their ability in a context that interests them. This is referred to as "competence". Meeting these three needs may be especially important during early adolescence, a period characterized by the increased desire for autonomy, peer orientation, salience of identity, and capacity for abstract thought (Eccles, Barber, Stone, \& Hunt, 2003).

One possible solution for facilitating long-term volunteerism is to collaborate with others and engage in common problem solving. This collaborative effort to cope with and resolve serious and emergent problems after a disaster, is explained by Markus and Kitayama's self-schema model. Certain cognitive processes guide collaborative problem solving through the interaction between the "independent self" and "interdependent self" (e.g., Markus \& Kitayama, 1991, 2010). In this model, when an independent self-schema organizes behavior, the primary referent is the individual's own thoughts, feelings, and actions. Alternatively, when an interdependent self-schema organizes behavior, the immediate referent is the thoughts, feelings, and actions of others with whom the person has a relationship. These interactions are guided by culturally prescribed tasks that require and encourage the development and reification of individual preferences, goals, beliefs, and abilities (which include creativity). Interactions with others produce a sense of self as connected to, related to, or interdependent with others.

This connection and interdependent relation with others is referred to as "Kizuna" in Japan since March 11, 2011; this refers to the way in which the minds and mentalities of two or more people are connected and strongly tied to each other. On March 11, 2011, a massive, magnitude-9.0 earthquake occurred off the Pacific coast in the northeastern part of Japan's Tohoku region, triggering catastrophic tsunami waves. According to the Japanese National Police Agency, there were 15,853 deaths and 3,283 people reported missing across 12 prefectures. After the earthquake, electricity, gas, and telephone services were disrupted in the region from anywhere between a week to several months; people in those areas needed food, clean water, medicine, clothing, temporary shelter, and financial donations. The disaster caused catastrophic damage throughout north eastern Japan, particularly in the three prefectures of Iwate, Miyagi, and Fukushima. One year later, rehabilitation and reconstruction work continues in the affected areas, but it has been expected that these recovery processes will take much longer than originally anticipated. For years to come, it will be important for children to continue cultivating hopes and dream. The needs for emergency relief and other humanitarian efforts still exist. 
However, this natural disaster gave individuals the opportunity to provide support and/or perform volunteer work within the affected areas. Short-term support was provided in order to enable rebuilding in both the middle and long term. When this type of environment emerges, it requires creativity, acceptance of material deprivation, and an acknowledgment of the fact that families are missing.

With such bleak conditions, self-integration and creativity are further conceptualized within the collective, collaborative paradigm of development. Repair efforts after the March 11 disaster were undertaken for the victims and residents of the affected areas in several phases: emergency response, recovery, reconstruction, and restoring normal life (Tan, 2011). These phases are complex, and they challenge people to shift, focus, and make instant decisions. People need to act creatively. People should also act collectively to regulate emotions and to ensure safety. During emergency response and recovery, stages of development may not happen sequentially but likely occur instantly, momentarily, and cyclically. The collective goal is simply to live safely with loved ones and gain basic resources. During the reconstruction and restoration of normal life stages, people are likely to conduct themselves according to more manageable and responsible sociocultural principles (Tan, Oie, \& Fujie, 2011).

As a contribution to the recovery and reconstruction process, many organizations volunteer with a yearlong project to review, monitor, and evaluate the multiple levels of relief work. Many projects impacted the relief effort in several areas of Tohoku early on, but the progress of recovery and reconstruction has been significantly delayed. Considering the scale of the damage caused by the disaster, it is necessary to promptly establish long-term plans that will lead to creative and valuable recovery. However, if successful achievement of creative recovery will be gradual, this might manifest a new creative growth model.

\subsection{Volunteerism Based on Prosocial Behavior to Resolve Social Problems}

People take action to benefit other individuals, social movements, and society in several ways (Snyder \& Omoto, 2008). Snyder and Omoto (2008) estimated that millions of people devote substantial amounts of time and energy volunteering every year in countries worldwide. Volunteers make an important contribution to communities across the spectrum of social endeavor in most countries and cultures. Volunteers are also of widespread importance to leisure insofar as volunteers constitute a major component within a sector's workforce through a variety of roles and contexts (Lockstone-Binney, Holmes, Smith, \& Baum, 2010). Volunteerism is recognized as an important source of sociability, satisfaction, and self-validation over the life course (Hendicks \& Curtler, 2004),

From a psychological perspective, research on volunteering has focused on seeking to understand volunteers' motivations (Lockstone-Binney, Holmes, Smith, \& Baum, 2010). Researchers and practitioners agree that little is understood as to what motivates volunteers directed to positive youth development, because most investigations on motivation has focused on the implicit processes behind individual motivated behaviors such as goal achievement, intrinsic/extrinsic motivation, amotivation. However, prosocial common goals are shared among people who are motivated in pursuing helping activities such as voluntarism. Some researchers in social psychology often observe motivation declines occurring at the group level, as evidenced by research comparing individual effort on independent versus interdependent selves (Markus \& Kitayama, 1991). Beyond this general decline in motivation, it is quite important to explore how to keep people's motivation to pursue common goals to recover from the serious disasters. Fortunately, in recent years, psychological studies assessing volunteerism have increased, and several theoretical models have been developed to explain volunteerism (e.g., Omoto \& Snyder, 1995, 2002; Grube \& Piliavin, 1996). The motivation to volunteer is a factor in some theoretical models and is important for understanding participation in volunteer services (Mannino, Omoto, \& Snyder, 2011).

Motivation is regarded as fundamental for creativity. During the 1970s and 1980s, Amabile (1982) stimulated interest in the relationship between motivation and creativity; she emphasized the direct relationship between intrinsic motivation and creativity (Amabile, 1979, 1982). According to Amabile, intrinsic motivation is needed to enhance creativity. Further, during the 1990s and 2000s, creativity and motivation have been discussed in self-determination theory proposed by Deci and Ryan. Motivation drives individuals' engagement, which in turn creates experiences that reinforce their motivation. Individuals who are intrinsically motivated are likely to think more strategically, generate more creative solutions, persist through difficulties, and learn more from their experiences (Ryan \& Deci, 2000). As far as students, undergraduates, and individuals who are motivated to engage in volunteering behaviors for victims in the disaster areas and work together, creative ideas, krafts, projects, and tools will come up with their spontaneous initiatives to support victims widely and looking ahead in future. 


\section{Volunteerism for Positive Youth Development}

Some psychologists have given particular attention to adolescence since it is a period when youth become more able to engage in a deliberate cultivation of their own development (e.g., Eccles, Barber, Stone, \& Hunt, 2003; Larson \& Rusk, 2011). Eccles and colleagues argue that volunteer activities provide opportunities to (a) acquire and practice specific social, physical, and intellectual skills that might be useful in a wide variety of settings, including school; (b) contribute to the well-being of one's community and develop a sense of agency as a member of one's community; (c) establish supportive social networks of peers and adults that can help in both the present and the future; and (d) experience and deal with challenges (Eccles, Barcer, Stone, \& Hunt, 2003). These suggestions are supported by both classic sociology studies assessing the relationship between extracurricular activities and school achievement and more recent research in leisure and interdisciplinary studies assessing adolescent development (Eccles \& Templeton, 2002).

Since March 11, 2011, there has been a growing interest in the developmental consequences of volunteering among the youth of Japan. Advocates for positive youth development argue that volunteer programs are needed to prepare youth for the transition into adulthood (Pittman, Tolman, \& Yohalem, 2005). To foster creative skills and competence among adolescence leads to develop useful knowledge and wide perspectives for recovering from the serious disaster. Then it will be connected to vocational behavior, future life planning, and career development as well as citizenship to contribute to share tasks to be resolved in the community.

\section{Theoretical Implications for the Development of Motivation and Creativity in Adolescence}

\subsection{The Role of Motivation to Enhance Volunteering Behaviors in Adolescence}

Motivation is an urgent issue for youth if they are to thrive in a complex global society. The quantity of information they need to acquire and their creative thinking abilities continue to increase in modern global society. The types of problems and opportunities that youth encounter as they come of age require motivation toward creativity and the ability to undertake challenging problem solving in difficult situations. Csikszentmihalyi (1990) identified a number of factors in a person's interaction with an activity that are associated with motivation and creativity. He included intrinsic motivation as a personal characteristic that contributes to creativity. A crucial point made by him is that this motivation comes from engagement with complexity. He noticed that complexity is present within difficult and challenging problems. He discovered that the experience of flow is not limited to leisure activities but could expand to interdisciplinary contexts.

When people are working in a constructive and collaborative environment, they are motivated to create new solutions from complex scenarios. Consequently, it is common for youth to experience flow in extracurricular and volunteer programs, a context in which youth feel that complex, unstructured challenges for improving their communities develop their creative leadership, altruism, and civic engagement (Larson, 2000). Larson described in a series of studies that these activities are developmental contexts for social integration. He argued that these activities connect youth to their community by fostering relationships with adults, peers, and family, and by promoting a prosocial set of norms. Larson also proposed that this pattern of social relatedness often continues into adulthood. In such challenging situations, motivation could facilitate more general development, including the development of emotional maturity, identity, social skills, and creativity (Csikszentmihalyi, 1990; Larson, 2000). Motivation predicts more open and creative processing of information. Research subjects assigned to intrinsically motivating conditions engage in greater exploration and are more likely to break set and formulate original creative solutions to problems (Amabile, 1983; Hennessey, 2000). In sum, motivations experienced by youth in these after-school and out-of-university programs might help activate episodes of deeper, expansive, and integrative meta-cognitive reasoning that lead to conscious developmental change.

Penner and colleagues defined volunteering as a prosocial behavior that occurs within the context of groups and large organizations (Penner, Dovidio, Piliavin, \& Schroeder, 2005). They argued that much of the work from the mid-1960s until the early 1980s investigated when people would help in emergency and nonemergency situations. Later researches and theories, during the 1980s and 1990s, considered why people help, examining processes that motivated prosocial action. Volunteering involves prosocial action in an organizational context, which is related to interpersonal helping (Penner, 2004). Again, volunteering behaviors seem to be encouraged by intrinsic motivation, sharing sympathized emotion among victims. To promote prosocial actions in adolescence, it is effective for youth to experience self-determined volunteering behaviors decided by themselves intrinsically. 


\subsection{Volunteerism Pre-and Post the Great East Japan Earthquake}

In this section, to begin with, volunteerism and prosocial behavior will be highlightened theoretically and next, mentioned volunteer interventions since the Great East Japan Earthquake. In Japan, volunteering has not been a requirement for high school graduation as is the case in some states in the US. Thus, volunteering behavior might be more intrinsically motivated in Japan. After the earthquake, several youth, adults, and elder citizens from Tokyo, Osaka, and other areas in Japan went to the Northern Japan to participate in volunteering during the recovery process.

Volunteerism has been investigated in two main disciplines: leisure and psychology. In leisure studies, tourism, sports, and events are major themes that have cultivated research questions (Stebbins, 1996). Stebbins (2000) conceptualized volunteering as a form of leisure that has been developed at the case of casual and serious leisure, including volunteering. He made an early observation lamenting the lack of crossover between the disciplinary boundaries of leisure and volunteer research, suggesting that neither field has been inclined to view its own subject matter through the other's perspective. Likewise, Mair, a leisure researcher, pointed out an important element of "multi-interdisciplinarity", which she contends is necessary in order to understand social change (Mair, 2012). Social change subsumes leisure and creativity from the standpoints of diverse research domains in the social sciences. Her earlier contribution (Mair, 2006) enumerates the difficulties with the notion of interdisciplinary research; she explained that partial understanding provides only limited opportunities for social struggle and meaningful social change.

These opinions are remarkable, because long-term social changes after a natural disaster are characterized by patience, declining moods, poverty, and the loss of people's homes. Specifically, Mair's opinions assess the contributions of philanthropy, which helps victims of natural disasters recover and contribute to people's well-being in a suffering society. However, in the current system, academic institutions are impediments to, rather than enablers of, interdisciplinary collaboration. Neither is interdisciplinary research the norm in most academic institutions nor is it typically rewarded (Oie, 2012).

\subsection{To Sustain Volunteerism for Further Recovery}

Volunteering after the disaster in Japan will be a long-term activity; thus, the processes related to the maintenance of this activity need to be considered. Snyder and Omoto (2008) defined a feature of volunteerism whereby volunteer activities must be delivered over a period of time-weeks, months, and years. They claimed that emergencies and disasters lead people to look for ways to become involved over the long term for a more sustained helping effect.

How did the March 11 earthquake affect volunteering? To answer this question, volunteer data from 2011 and 2012 were assessed. Figure 1 presents the adjusted 2011 to 2016 monthly totals for the number of people who registered with the Disaster Volunteer Center in Japan and volunteered in the three Tohoku prefectures of Iwate, Miyagi, and Fukushima. According to research from the Disaster Volunteer Center in Japan in 2017, the number of participants volunteering until 2016 in Tohoku had declined each month after March 2011.

As Penner (2004) discussed, among most contemporary social psychologists, the phrase "pro-social behavior" still brings to mind the notion of bystander interventions in an emergency. A similar notion might be brought to mind among several volunteers after they have previously served as volunteers. Penner categorized volunteerism into three types. (1) It is a planned action; people think and weigh their options before they make the decision to volunteer; in this respect, volunteerism can be contrasted with bystander intervention in an emergency, in which immediate, affective reactions play a primary role in people's decisions about whether or not to intervene. (2) It is a long-term behavior; most people who volunteer continue this activity for an extended period of time. This can be contrasted with bystander interventions, which are usually quite time limited. (3) It requires "nonobligated" helping (Omoto \& Snyder, 1995). The sense of obligation results from external pressure such as school credit for entrance examination at universities, rewards, and admiration among others and leads to extrinsic motivation.

Thus, volunteerism may simply be a much more common (and more important) form of prosocial actions that go beyond helping a stranger in an emergency. Volunteering was explicitly and widely encouraged by public officials and numerous governmental and private organizations in the weeks that followed the Great East Japan Earthquake. In spite of these efforts and in spite of the acute necessity in areas that lack volunteer participants, why has volunteering assistance declined? Is there an important method for resolving this extremely severe situation and increasing volunteer rates? A crucial suggestion by Matsuba et al. (2007) might help maintain volunteer motivation. Two major theoretical models have been proposed to outline the factors that assist sustained volunteering over an extended period of time (Matsuba, Hart, \& Atkins, 2007): the volunteer process 
model proposed by Omoto and Snyder $(1995,2002)$ and the role identity model proposed by Grube and Piliavin (2000). In the volunteer process model, sustained volunteerism is determined mainly by the extent to which there is a match between the motivation that originally led a person to volunteer and that person's actual experiences as a volunteer. Consistent with this model, personal motivation, social and organizational support, and satisfaction with the volunteer experience are crucial factors in sustaining volunteer activity. These factors could be integrated in an interdisciplinary fashion by a multilevel approach relevant to social psychology, developmental psychology, and organizational psychology.

Encouraging collaboration among many disciplines and designing research activities around critical problems are important steps in promoting problem-focused research. The communities affected by Japan's 2011 earthquake must continue to work together to address the complex challenges that remain. In the next section, I discuss two psychological concepts, identity formation and collaborative creativity, that connect psychology to more global social issues.

\section{Discussion: To Maintain Volunteering Consistently: The Role of Identity Formation, Collaborative Creativity, and Community Citizenship}

Throughout this paper, I have mentioned studies examining the relation of motivation to sustaining creativity and volunteering over the long term. I now suggest an integration of various psychological behaviors. Below, I provide some examples.

\subsection{Identity Formation}

Volunteering experiences in adolescence will enhance identity formation in future. Past experiences can add meaning to one's life and contribute to one's present identity. The extent to which individuals think of themselves in terms of a particular social identity typically varies as a function of situational cues. Fishbach, Henderson, and Koo (2011) argued that social identity increases in strength when individuals achieve goals set at the group level rather than at the personal level. This is especially the case when people share similar characteristics, such as an affiliation with the same organization. When group identification is strong, individuals merge their senses of self with their group identities and think about others as part of their extended selves; the group becomes part of the individuals' identities. If a person has incurred losses during a disaster, his/her life could change, integrating appalling and cruel experiences that subsequently lead to central life events. Piliavin and her colleague proposed a role identity model examining the relationship between perceived expectations from significant others and role identity. Role identity is defined as the extent to which a particular role becomes part of the person's identity (Grube \& Piliavin, 2000). For the purposes of this paper, the role of volunteer in the formation of youth identity was explored. In addition, the role identity model posits that organizational variables and the experiences and behaviors associated with actual volunteering facilitate the development of a volunteer role identity, which is the immediate precursor of sustained volunteering.

To identify adolescent development, such activities should help adolescents clarify their personal identity while maintaining relationships with specific sets of peers and adults. Involvement in some volunteer organization links an adolescent to a set of similar peers and relationships with adults. Volunteer activities can facilitate adolescents' developmental need for social relatedness (Eccles, Barcer, Stone, \& Hunt, 2003).

\subsection{Collaborative Creativity}

Collaborative creativity is essential in constructing life. During collaboration, people work for the attainment of common goals. As Tan (2011) claims, creativity is the human ability to generate new and useful ideas or a process of reworking experiences to create meaning. Every individual has the potential to be creative in generating thoughts and taking action. Human beings are capable of recalling and reworking our experiences and realities. People create symbols, representations, and expressions to represent our experiences and realities. Therefore, creative imaginations contribute to and enrich cultural artifacts and activities.

Besides, collaboration can occur at basic (coordination), intermediate (cooperation), or advanced (co-construction) levels (Kaptelinin \& Nardi, 2006). During coordination, people work independently toward a common goal. During cooperation, people are aware of others who work toward the same goals. Those who cooperate relate their individual goals to collective goals, and they adjust their individual actions to facilitate the attainment of these collective goals. During co-construction, people cooperate, and they collectively redefine the object toward which they are working and the activity by which the object is edified; this may lead to a major change in the group's activities. Collaborative creativity emerges when people engage in co-construction; it involves changes in activity that lead to the emergence of new meanings. 


\subsection{Community Citizenship}

Citizenship is important to consider sustaining volunteerism. Recent discussions related to volunteerism have emphasized the importance of considering community citizenship (Yates \& Youniss, 1996; Gagné \& Deci, 2005). Yates and Youniss reported that community service is assumed to not only help the community but also promote prosocial development among participants. Community service is defined as involvement in activities that help others, including earthquake victims. Community service and activism during youth are associated with lifelong involvement in voluntary organizations (Youniss, McLellan, \& Yates, 1997).

Volunteerism based on prosocial, altruistic, and other-oriented behavior creates a heightened sense of concern and community among typical supporters of different causes represented by various organizations and communities. The substantial increases in volunteering merit some discussion. It seems clear that a very large number of people felt a need to volunteer after the disaster in Japan. Youniss and colleagues mentioned that such community service studies have been conducted by researchers from a variety of disciplines, including education, psychology, and sociology. They emphasized that it is necessary to develop a theoretical framework with which to assess interdisciplinary issues.

\subsection{Conclusion}

Specific environments, such as disasters, and motivation and creativity influence volunteerism. In addition to exploring these phenomena, this examination also discussed how, in contrast, motivation and creativity could be developed and increase diversity after a person intended or participated in volunteering. At the same time, in contrast, it is indispensable to consider how motivation and creativity could be developed and increase diversity after a person intended or participated in volunteering. Volunteerism is a motivated phenomenon, propelled by motivational forces that lead individuals to seek out volunteer activities and to surmount barriers that impede their participation and sustained involvement (Mannino, Snyder, \& Omoto, 2011). Volunteer motivations develop, shift, and will be integrated over time. Motives can vary with life circumstances and lifespan development. Connections to a psychologically defined community, which result from volunteer experiences and motivate later action, might predict the extensiveness of people's prosocial actions. Research on volunteerism, which stems from motivation and creativity, is able to contribute to connections between psychology and other social science disciplines and can facilitate the development of interdisciplinary collaborations and perspectives (Penner, Dovidio, Piliavin, \& Schroeder, 2005).

In summary, volunteering is a prosocial and altruistic behavior that might extend and sustain across time and lifespan. Volunteering provides considerable benefits to others, especially victims of a disaster. Volunteering could also have significant psychological and physical benefits for the volunteer. In the future, a more integrative understanding of volunteerism across the domains of psychology and social sciences, which include the area of motivation and creativity, is necessary. The study of prosocial behavior still has much to contribute to psychology and related disciplines.

Implications for teacher education program at university and college can be also indicated in this paper. Positive youth development will be formed throughout volunteering behavior in adolescence. Then it will be effective for prospective teachers to experience volunteering during their undergraduate periods. When they become teachers at schools, they can teach students how they felt emotion in volunteering by deciding everything in their own opinions and acquired creative skills and/or collaborative corporation. Volunteering as extracurricular activities for undergraduate and prospective teachers can strengthen their own and students' rich and deep life course in future.

\section{References}

Amabile, T. M. (1979). Effects of external evaluations on artistic creativity. Journal of Personality and Social Psychology, 37, 221-233. https://doi.org/10.1037/0022-3514.37.2.221

Amabile, T. M. (1982). The social psychology of creativity: A consensual assessment technique. Joumal of Personality and Social Psychology, 43, 997-1013. https://doi.org/10.1037/0022-3514.43.5.997

Amabile, T. M. (1983). Social psychology of creativity: A componential conceptualization. Journal of Personality and Social Psychology, 45, 357-376. https://doi.org/10.1037/0022-3514.45.2.357

Amabile, T. M., Goldfarb, P., \& Brackfield, S. C. (1990). Social influences on creativity: Evaluation, coaction, and surveillance. Creativity Research Journal, 3, 6-21. https://doi.org/10.1080/10400419009534330 
Disaster Volunteer Center in Japan. (2017). Number of participants volunteering in three prefectures of the Tohoku region. Retrieved from https://www.saigaivc.com/2017/02/24/東日本大震災ボランティア活動者 数の推移/(Japanese)

Eccles, J. S., \& Templeton, J. (2002). Extracurricular and other after-school activities for youth. In W. S. Seceda (Ed.), Review of Educational Research (Vol. 26, pp. 113-180). Washington D.C.: American Educational Research Association Press.

Eccles, J. S., Barber, B. J., Stone, M., \& Hunt, J. (2003). Extracurricular activities and adolescent development. Journal of Social Issues, 59, 865-889. https://doi.org/10.1046/j.0022-4537.2003.00095.x

Fishbach, A., Henderson, M. D., \& Koo, M. (2011). Pursuing goals with others: Group identification and motivation resulting from things Done versus things left undone. Journal of Experimental Psychology: General, 140, 520-534. https://doi.org/10.1037/a0023907

Gagné, M., \& Deci, E. L. (2005). Self-determination theory and work motivation. Journal of Organizational Behavior, 26, 331-362. https://doi.org/10.1002/job.322

Grube, J., \& Piliavin, J. A. (2000). Role-identity, organizational experiences, and volunteer performance. Personality and Social Psychology Bulletin, 26, 1108-1119. https://doi.org/10.1177/01461672002611007

Hendricks, J., \& Curtler, S. J. (2004). Volunteerism and sociemotional selectivity in later life. The Journals of Gerontology, 59, 251-257. https://doi.org/10.1093/geronb/59.5.S251

Hennessey, B. A. (2000). Self-determination Theory and the Social Psychology of Creativity. Psychological Inquiry, 11, 293-298.

Kaptelinin, V., \& Nardi, B. (2006). Acting with Technology: Activity Theory and Interaction Design. Cambridge: MIT Press.

Larson, R. W., \& Rusk, N. (2011). Intrinsic Motivation and Positive Development. In R. M. Lerner, J. V. Lerner, \& J. B. Benson (Eds.), Positive Youth Development. Advances in Child Development and Behavior (Vol. 41, pp. 89-130). Burlington: Academic Press. https://doi.org/10.1016/B978-0-12-386492-5.00005-1

Lockstone-Binney, L., Holmes, K., Smith, K. M., \& Baum, T. G. (2010). Volunteers and volunteering in leisure: Social science perspectives. Leisure Studies, 29, 435-455. https://doi.org/10.1080/02614367.2010.527357

Mair, H. (2006). Potential of interdisciplinarity for leisure research. Leisure Sciences, 28, 197-202. https://doi.org/10.1080/01490400500484099

Mair, H. (2012). Meeting the Challenges of Uncertain Times: The Importance of (Critical) Interdisciplinary Research. Creativity and Leisure, 1, 171-182.

Mannino, C. A., Snyder, M., \& Omoto, A. M. (2011). Why do people get involved? Motivations for volunteerism and other forms of social action. In D. Dunning (Ed.), Social motivations (pp. 127-146). New York: Psychology Press.

Markus, H. R., \& Kitayama, S. (2010). Cultures and Selves: A Cycle of Mutual Constitution. Perspectives on Psychological Science, 5, 420-430. https://doi.org/10.1177/1745691610375557

Markus, H., \& Kitayama, S. (1991). Culture and the self: Implications for cognition, emotion, and motivation. Psychological Review, 98, 224-253. https://doi.org/10.1037/0033-295X.98.2.224

Matsuba, M. K., Hart, D., \& Atkins, R. (2007). Psychological and social-structural influences on commitment to volunteering. Journal of Research in Personality, 41, 889-907. https://doi.org/10.1016/j.jrp.2006.11.001

Oie, M. (2012). The Intersection of Psychology and Leisure Studies after March 11, 2011, in Japan: A Commentary on Mair's "Meeting the Challenges of Uncertain Times: The Importance of (Critical) Interdisciplinary Research". Creativity and Leisure, 1, 189-194.

Omoto, A. M., \& Snyder, M. (1995). Sustained helping without obligation: Motivation, longevity of service, and perceived attitude change among AIDS volunteers. Journal of Personality and Social Psychology, 68, 671-686. https://doi.org/10.1037/0022-3514.68.4.671

Omoto, A. M., \& Snyder, M. (2002). Considerations of community: The context and process of volunteerism. American Behavioral Scientist, 45, 846-867. https://doi.org/10.1177/0002764202045005007

Penner, L. A. (2004). Volunteerism and social problems: Making things better or worse? Journal of Social Issues, 60, 645-666. https://doi.org/10.1111/j.0022-4537.2004.00377.x 
Penner, L. A., Dovidio, J. F., Piliavin, J. A., \& Schroeder, D. A. (2005). Prosocial behavior: Multilevel $\begin{array}{lllll}\text { perspectives. Annual } & \text { Review }\end{array}$ https://doi.org/10.1146/annurev.psych.56.091103.070141

Ryan, R. M., \& Deci, E. L. (2000). Self-determination theory and the facilitation of intrinsic motivation, social $\begin{array}{lllll}\text { development, and } \quad \text { well-being. } & \text { American }\end{array}$ https://doi.org/10.1037/0003-066X.55.1.68

Snyder, M., \& Omoto, A. M. (2008). Volunteerism: Social Issues Perspectives and Social Policy Implications. Social Issues and Policy Review, 2, 1-36. https://doi.org/10.1111/j.1751-2409.2008.00009.x

Stebbins, R. A. (1996). Cultural tourism as serious leisure. Annals of Tourism Research, 23, 948-950. https://doi.org/10.1016/0160-7383(96)00028-X

Stebbins, R. A. (2000). Obligation as an aspect of leisure experience. Journal of Leisure Research, 32, 152-155.

Tan, A. G. (2011). Creativity for constructive growth: A synthesized paradigm for positivity and care after Japan-3.11 incidents. Keynote address at the $33^{\text {rd }}$ Japan Creativity Society Annual Conference in Tokyo (October 8), Tokyo, Japan.

Tan, A. G., Oie, M., \& Fujie, Y. (2011). Self-regulated Learning and Creativity in Constructing Life. In The 33th Research Convention of Japan Creativity Society, symposium (Japanese).

Weinstein, N., Deci, E. L., \& Ryan, R. M. (2011). Motivational Determinants of Integrating Positive and Negative Past Identities. Journal of Personality and Social Psychology, 100, 527-544. https://doi.org/10.1037/a0022150

Yates, M., \& Youniss, J. (1996). A Developmental Perspective on Community Service in Adolescence. Social Development, 5, 85-111. https://doi.org/10.1111/j.1467-9507.1996.tb00073.x

Youniss, J., McLellan, J. A., \& Yates, M. (1997). What we know about engendering civic identity. American Behavioral Scientist, 40, 620-631. https://doi.org/10.1177/0002764297040005008

\section{Appendix}

\section{Appendix A}

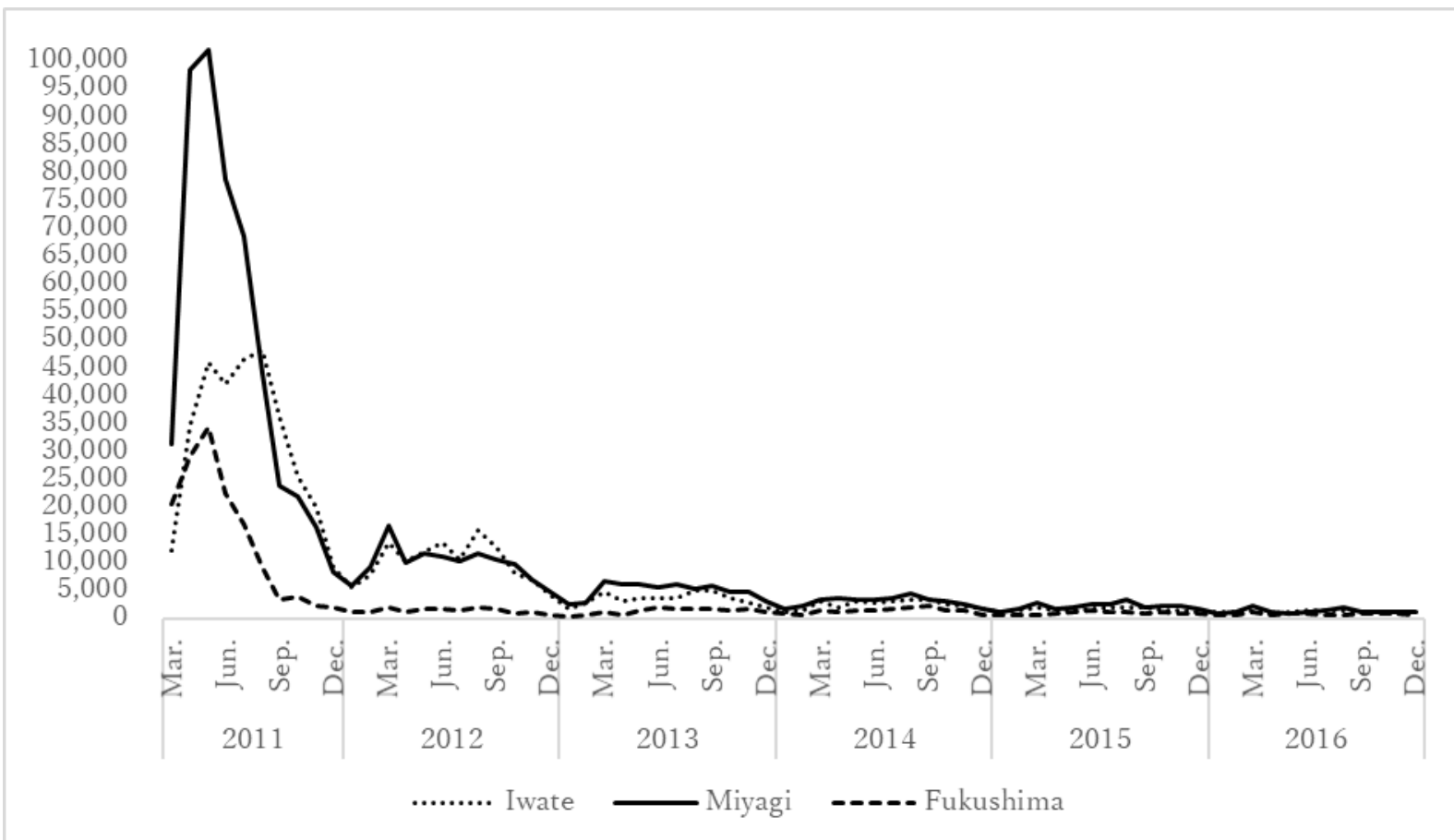

Figure 1. Number of participants volunteering in three prefectures of the Tohoku region in 2011-2016 (Created by author from Disaster Volunteer Center in Japan, 2017) 


\section{Copyrights}

Copyright for this article is retained by the author(s), with first publication rights granted to the journal.

This is an open-access article distributed under the terms and conditions of the Creative Commons Attribution license (http://creativecommons.org/licenses/by/4.0/). 